\title{
Study on respiratory organ of Schistura rupicola McClelland from Lamphengwa Khola, Gajurmukhi VDC, Ilam, Nepal
}

\author{
A. Anshumala and B.R. Subba* \\ Department of Zoology, Post Graduate Campus, Tribhuvan University, Biratnagar, Nepal \\ *E-mail: subbabharat@yahoo.com
}

\begin{abstract}
Gill structure of Schistura rupicola McClelland collected from Lamphengwa Khola, Gajurmukhi Village Developmemt Committee, Ilam, Nepal was studied by double staining in haematoxylin and eosin, and taking photomicrographs by digital camera and light microscope. Gill-rakers are present on both sides of gill-head. The gill bar is "V" shaped. The efferent branchial artery is larger than afferent branchial artery. The inter-branchial septum is $20.16 \%$ of holo-branch. The first gill-arch filaments of the mid region of the posterior hemi-branches are longer. In other gill-arches, the lengths of the posterior hemi-branches are greater than their counterparts on the anterior hemi-branch.
\end{abstract}

Key words: Respiratory organ, Schistura rupicola, Ilam.

\section{Introduction}

Schistura rupicola McClelland is a small sized hill-stream loach which inhabits sandy and stony bottom of hill-streams. This fish is available in Lamphengwa khola a small rivulet located in Gajurmukhi VDC of Ilam district, Nepal. It is locally called "Gadera" and its body is almost cylindrical in shape suitable for hill-stream adaptation. The gill is a complicated organ and helps in gaseous exchange in aquatic medium and, osmo-regulation and circulation of hormones. The gill structure has been studied in details by several researchers like Munshi (1960), Muir and Kendall (1968), Hughes and Morgan (1973), Hughes (1980), Hughes and Umezawa (1983), Maina and Maloiy (1986), Rooj (1993), Ishimastu and Itazawa (1993), Singh (1996), Subba (1999), Bhattacharya and Subba (2003), Dahal (2003). In the present study an attempt has been made to show and delineate morpho-anatomical structures of S. rupicola gill.

\section{Materials and Methods}

A large number of fishes were collected with the help of local fishermen and a few were preserved in $70 \%$ alcohol. The gills of a few fish were removed carefully with the help of a sharp blade and a forcep then cut into small suitable pieces. The pieces were preserved in freshly prepared Bouin's fluid for 21 hours. Three changes were made within 21 hours at a lapse of 7 hours then specimens were transferred to $70 \%$ alcohol for further work. The fixed gill pieces were decalcified in 5\% HNO3 in ethanol for 72 hours. Paraffin blocks were prepared and sections of $5 \mathrm{u}$ to $6 \mathrm{u}$ were cut in 3 dimensions with reference to gill filaments. They were double stained by haematoxylin and eosin Permanent slides were prepared and necessary light micro-photographs were taken to study the structures in details.

\section{Results and Discussion}

The branchial apparatus of $S$. rupicola comprises four pairs of moderately developed gillarches. The gills remain covered with operculum. The ventral part of gill is more interiorly placed than the dorsal (Plate 1, Fig. 3). The epi and cerato-branchial parts of the gill arches bear 
filaments whereas hypo and pharyngo-brachial parts are without filaments. Each gill may be divided into upper (dorsal), middle and lower (ventral) regions. The dorsal portion is bent at right angle from the remaining middle and ventral portions (Plate 1, Figs. 4-7).

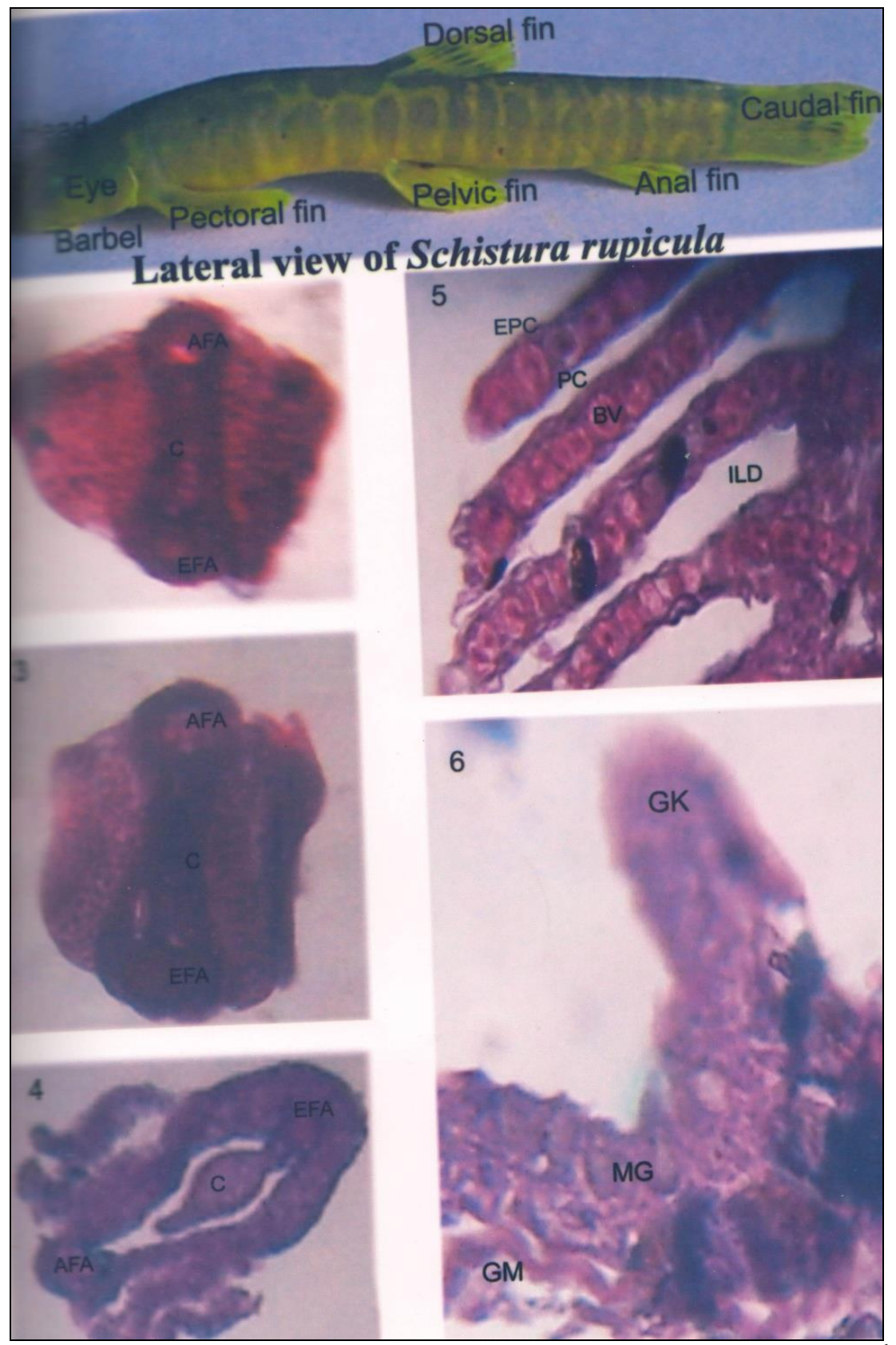

Plate 1. S. rupicola: Figures 1. Lateral view, 2. Front view, 3. Position of Gills, $4.1^{\text {st }}$ gill arch, 5. $2^{\text {nd }}$ gill arch, 6. $3^{\text {rd }}$ gill arch, 7. $4^{\text {th }}$ gill arch. (ILA- Inter lamellar space, SL - Secondary lamella, TB - Taste bud, GK - Gill raker, GH - Gill head, C - Cartilage, GA - Gill, EBA - efferent branchial artery, ABA - afferent branchial artery, GF gill filament, BV - blood vessel, MG - Mucous gland, ABM - Abductor muscle, IBS - Inter branchial septum) 


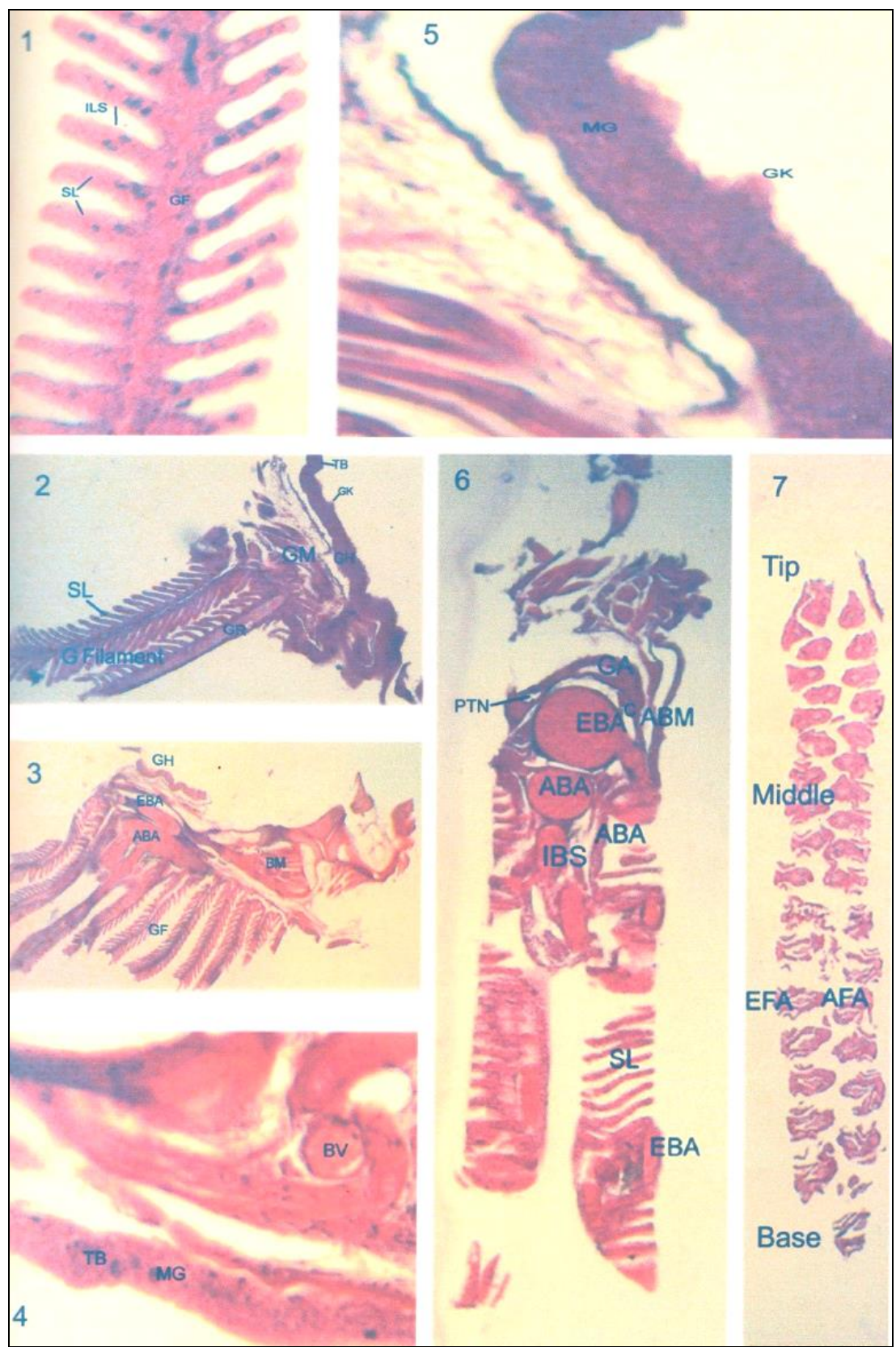

Plate 2. S. rupicola: Horizontal sections: Figures 1. passing through gill, 2. of gill showing taste bud, gill raker and secondary lamella (40x), 3. of gill showing afferent branchial artery, efferent branchial artery (40x), 4. of gill of showing blood vessel and mucous gland; Transverse sections: 5. of gill showing mucous gland and gill rakers (40x); Vertical sections: 6. of gill showing pretrematic nerve, secondary lamella afferent and afferent branchial artery abductor muscle (40x), 7. of gill showing arrangement of secondary lamella in tip, middle, and base region (40x). (ILA - Inter lamellar space, SL - Secondary lamella, TB - Taste bud, GK - Gill raker, GH Gill head, C - Cartilage, GA - Gill, EBA - efferent branchial artery, ABA - afferent branchial artery, GF - gill filament, BV -blood vessel, MG - Mucous gland, ABM - Abductor muscle, IBS - Inter branchial septum) 
The abductor and adductor muscle units are discernible. These muscle units help in the movements of gill filaments in natural condition. Each gill consists of two parts a $>$ the gill head region $b>$ the gill filament region.

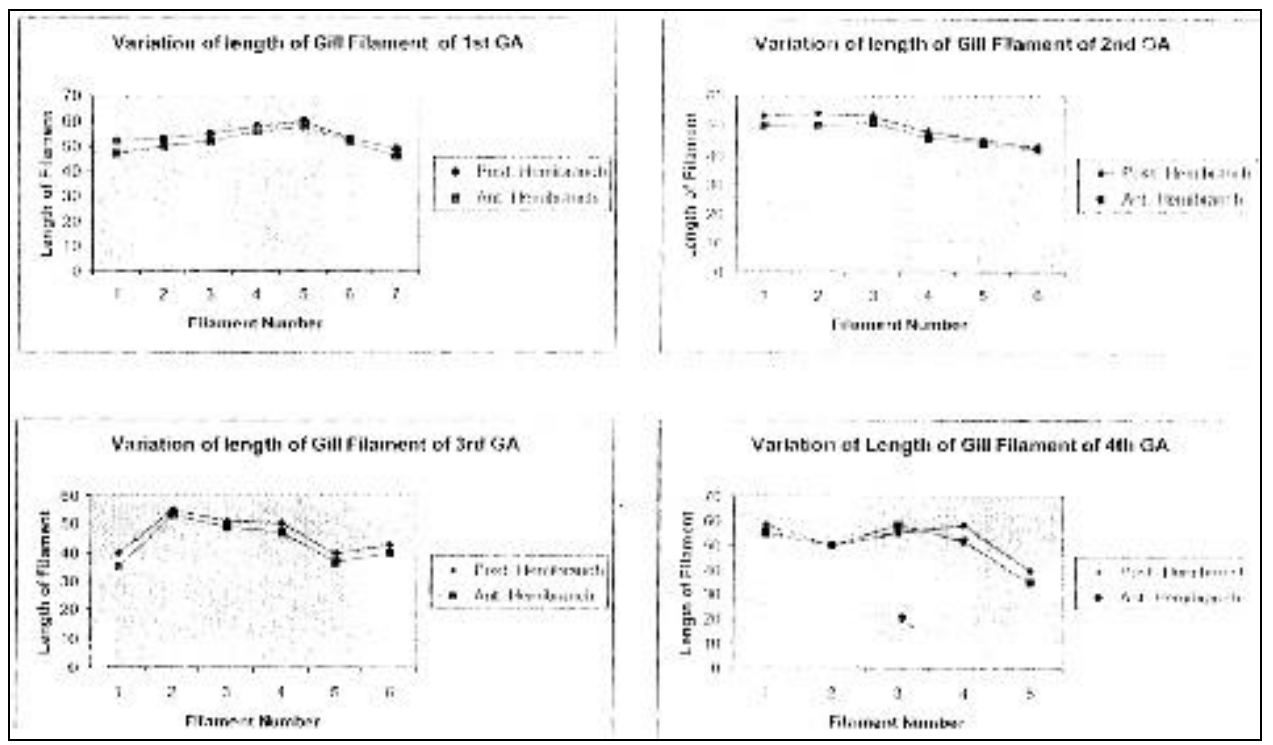

Figure 1. Showing the length of gill filament along the four gill arches.

\section{Gill head region}

The histological section of the gill head region is internally provided with a branchial arch for support of afferent and efferent blood vessels, nerves and abductor muscles. The triangular shaped bony structure of the bronchial arch, the gill bar appears to have shrunken inwardly in the form of an inverted "V" to lodge the said blood vessels and nerves. Each branchial arch has one afferent and one efferent branchial artery. Slightly above the efferent branchial vessel are located two nerves, called pre-trematic and post-trematic nerves respectively (Plate 2, Figs. 46). A thick layer of epithelium covers each gill head region, which thins out at the sides. Below the epithelium lies a thick layer of club cells. The light microscopic study of epithelium reveals the presence of mucous glands, taste buds and small-undifferentiated cells. Gill rakers are usually situated in the gill head region. They are well developed filliform structures. They are conical in shape. The epithelium, which covers the gill-rakers, contains a large number of mucous glands and taste buds. In S. rupicola, all four gill-arches were slightly different from the rest of the gill-arches. The first, second, and third gill arches have gill rakers on both sides of the gill head whereas the fourth gill arch has gill rakers only on one side. The number of gill raker on the first, second third and fourth gill-arches are eighteen, fifteen, sixteen and seven.

\section{Gill filament region}

The epi-branchial and cereto-branchial regions give rise to two rows of gill filaments (primary lamellae). The histology of the gill of $S$. rupicola shows many deviations from the histology of teleost gill. It has comparatevil short, poorly developed inter-branchial septum which is nearly $20.16 \%$ of the holo-branch. The inter-branchial septum is longer in other hill-stream fishes e.g., Garra, Danio, Glyptothorax, Amblyceps. The length of inter-branchial septum of S. rupicola is nearly similar to that of $G$. telchitta which is 16 to $20 \%$ of holo-branch, because both are bottom 
dwellers. Gill filaments are absent in S. rupicola through it is present in other hill stream fishes e.g., Glyptothorax pectinopterus, Pleuronectes americanus. The anterior and posterior hemibranchs of each gill showed variations in the length of filaments at different regions of the gillarches. In the first gill-arch, filaments of mid-region of the posterior hemi-branches are longer. In other gill-arches, the lengths of the posterior hemi-branches are greater than that on the anterior hemi-branch (Fig. 1). The adductor muscles arise from the basal extremities of the gill regions of hemi-branches and are inserted on the gill rays of opposite hemi-branch. The filaments of the opposite hemi-branch are alternate to each other (Plate 2, Fig.6). The secondary lamellae are densely packed, well developed leaf like structure. They are arranged alternately in a slightly slanting fashion on both sides of primary filament (Plate 2, Figs. 1-2) facilitating the flow of water between the lamellae and form an efficient gill-sieve. The secondary lamellae are varied in number in different region. It is 11 in tip, 9 in middle and 7 in base region. The interlamellar space is also varied. It is $0.5 \mu \mathrm{m}$ in tip, $1.2 \mu$ in middle and $1.0 \mu$ in the base region. These observations are in accordance with the findings of Grigg (1970) and Wright (1973). The space between the proximal margin of secondary lamellae and septum forms a channel for distribution of water along the length of filament and may be called as "water-channel".

\section{Acknowledgement}

The first author is thankful to the Department of Zoology, Post Graduate Campus, Biratnagar for providing laboratory facilities during study period.

\section{References}

Bhattacharya, H. \& B.R. Subba 2003. Structure of respiratory organs of Esomus dandricus (Ham). Our Nature 1: 49-52.

Dahal, A. 2003. Structure of gills of Xenentodon cancila (Ham) Our Nature 1: 72-73.

Grigg, G.C. 1970. Water flow through the gills of port Jackson Sharks. J. Exp. Biol. 52: 565-568.

Hughes, G.M. 1980. Functional morphology of gills, pp. 15-36. In Epithelial transport in the lower vertebrates (Ed. B. Lahlou), Cambridge Univ. Press.

Hughes, G.M. \& M. Morgan 1973. The structure of fish gills in relation to their respiratory function. Biol. Rev. 48: 419-475.

Hughes, G.M. \& S.I. Umezawa 1983. Gill structure of the yellow tail and frog fish. Japan. J. Ichthyol. 30(2): 176-183.

Ishimastu, A. \& Y. Itazawa 1993. Anatomy and physiology of the respiratory system in air-breathing fish, Channa argus. In Advances in Fish Research. pp. 55-70.

Maina, J.N. \& G.M.O. Maloiy 1986. The morphology of the respiratory organs of the African airbreathing catfish (Clarias mossambicus): A light electron and scanning microscopic study, with morphometric observations. J. Zool., London. 209: 421-445.

Muir, B.S. \& J.I. Kendall 1968. Structural modification in the gills of tunas and some other oceanic fishes. Copeia 2: 388-398.

Munshi, J.S.D. 1960. The structure of gills of certain freshwater teleosts. Ind. J. Zool. 1(3): 135-174.

Rooj, N.C. 1993. Structure of respiratory organs of the stone Ophiocephalus, Garra (Discognathus) lamata (Ham) Cyprinidae. Columban J. Life Sci. 1(1): 15-18.

Singh, B.R. 1996. On the gill structure of a cobitid fish, Lepidocephalichthys guntea (Ham) Japan. J. Ichthyol. 14: 103-106.

Subba, B.R. 1999. Structure and function of respiratory organ of a hill stream fish Glyptothorax telchitta (Ham), T.M. Bhagalpur University, Bhagalpur, India. (Ph.D. Thesis)

Wright, D.E. 1973. The structure of the gills of elasmobranch, Scyliorhinus canicula (L). Z. Zellforsch. 144: 489-509. 